\title{
Improvement and enhancement of antibladder carcinoma cell effects of heteronemin by the nanosized hyaluronan aggregation
}

This article was published in the following Dove Press journal:

International Journal of Nanomedicine

29 March 2016

Number of times this article has been viewed

\author{
Han Hsiang Huang' \\ Shyh Ming Kuo ${ }^{2}$ \\ Yi-Jhen $\mathrm{Wu}^{2}$ \\ Jui-Hsin $\mathrm{Su}^{3}$
}

'Department of Veterinary Medicine, National Chiayi University, Chiayi City, ${ }^{2}$ Department of Biomedical Engineering, I-Shou University, Kaohsiung City, ${ }^{3}$ National Museum of Marine Biology and Aquarium, Pingtung, Taiwan
Correspondence: Han Hsiang Huang Department of Veterinary Medicine, National Chiayi University, 580 Xinmin Road, Chiayi City 60054, Taiwan Tel +88652732952 Email hhuang@mail.ncyu.edu.tw
Abstract: The effects against tumors exerted by marine active compounds have been highlighted and investigated. Polymeric nanoparticles made from biodegradable and biocompatible molecules such as hyaluronan (HA) and chitosan (CHI) are able to aggregate the compounds to enhance their activities against tumor cells and reduce the toxicity on normal cells. Here, we extensively examined the antitumor activities and the mechanisms of $\mathrm{HA} / \mathrm{CHI}$ nanoparticles-aggregated heteronemin (HET) extracted from the sponge Hippospongia sp. The half-maximal inhibitory concentration $\left(\mathrm{IC}_{50}\right.$ ) of pure HET toward T24 bladder carcinoma cells is $\sim 0.28 \mu \mathrm{g} / \mathrm{mL}$. Pure HET from 0.2 to $0.8 \mu \mathrm{g} / \mathrm{mL}$ and HA nanoparticles-aggregated HET at 0.1 and $0.2 \mu \mathrm{g} / \mathrm{mL}$ significantly reduced T24 cell viability. Compared to pure HET, HA nanoparticles/HET aggregates showed much weaker viability-inhibitory effects on L929 normal fibroblasts. HET dose-dependently suppressed cancer cell migration as HA/CHI nanoparticles-aggregated HET displayed stronger migration-inhibitory effects than pure HET. Flow cytometric analysis showed that pure HET increased early/total apoptosis and JC-1 monomer fluorescence, while HA/CHI nanoparticlesaggregated HET induced higher apoptosis and JC-1 monomer rates than pure HET, suggesting that aggregation of HA nanoparticles offers HET stronger apoptosis-inducing capacity through mitochondrial depolarization. Western blot analysis showed that HA nanoparticles-aggregated HET further increased mitochondrial-associated, caspase-dependent and caspase-independent, as well as endoplasmic reticulum stress-related factors in comparison with pure HET. These data indicated that pure HET possesses cytotoxic, antimigratory, and apoptosis-inducing effects on bladder cancer cells in vitro, and its induction of apoptosis in bladder carcinoma cells is mainly caspase dependent. Moreover, HA nanoparticle aggregation reinforced the cytotoxic, antimigratory, and apoptosis-inducing activities against bladder carcinoma cells and attenuated the viability-inhibitory effects on normal fibroblasts. This aggregation reinforces antibladder carcinoma effects of HET via diverse routes, including mitochondrial-related/caspase-dependent, caspase-independent, and endoplasmic reticulum stress-related pathways. The current data also strongly suggested that $\mathrm{HA} / \mathrm{CHI}$ nanoparticles-aggregated HET would be a potential treatment for urothelial cancer in vivo.

Keywords: heteronemin, hyaluronan, chitosan, nanoparticle, bladder carcinoma cells

\section{Introduction}

Urothelial carcinoma (UC) is one of the most common tumors in addition to prostate (or breast) cancer, lung cancer, and colorectal cancer in the world. Bladder tumors are contributing $90 \%-95 \%$ of UCs. Bladder cancer accounts for the sixth most common cancer among men (19th in women) in an estimated 14.1 million cancer cases around the world in 2012. The importance of bladder cancer and its therapies should 
be underlined. In all, $>90 \%$ of cancer cases in the bladder are present as transitional-cell (urothelial) carcinoma. ${ }^{1-3}$ Urothelial bladder cancer has significant morbidity, mortality, and impact on public health. ${ }^{3}$ Approximately $75 \%$ of diagnosed urothelial bladder cancer is present as superficial and nonmuscle-invasive UC as the rest is classified into aggressive muscle-invasive UC. Surgical resection, intravesical chemotherapy, and immunotherapy have been used to treat nonmuscle-invasive UC, and multimodality therapy, such as cystectomy and chemotherapy, is more appropriate for muscle-invasive UC. ${ }^{4}$ Methotrexate, vinblastine, doxorubicin, and cisplatin were chemotherapeutic agents used to treat urothelial bladder cancer with $\sim 50 \%$ response rate $^{5}$ and a survival of 15.2 months in a large randomized Phase III study. ${ }^{6}$ However, methotrexate, vinblastine, doxorubicin, and cisplatin were associated with significant toxicities such as neutropenia and its infectious complications, as well as significant mucositis and a $4 \%$ drug-related death rate. ${ }^{7,8}$ On the other hand, gemcitabine plus cisplatin showed similar response rate (46\%) and survival time (14.0 months) but provided a better safety profile and tolerability. 5,6 Thus, the role of gemcitabine plus cisplatin as a standard of care in patients with locally advanced and metastatic transitional-cell carcinoma has been reinforced. ${ }^{6}$ Nonetheless, it is still necessary to discover new effective agents against urothelial bladder cancer for possible higher response rate, longer survival time, and better therapeutic strategies.

Natural compounds extracted from marine sponges and soft corals have been found to possess bioactive effects such as anti-inflammatory, antimicrobial, and antitumor activities. In particular, marine sponges have been shown to contain abundant secondary metabolite triterpenoids. It has been found that several natural compounds from soft corals have cytotoxic and apoptosis-inducing effects against melanoma cells, hepatocellular carcinoma cells, and bladder cancer cells in our previous studies. ${ }^{2,9,10}$ Heteronemin (HET) is a known sesterterpenoid extracted from the sponge Hippospongia sp. This natural marine compound was found to inhibit the enzyme protein farnesyltransferase and reduce the viability of leukemia cells, colon cancer cells, and breast cancer cells. ${ }^{11,12}$ The potential inflammation inhibitory and apoptosis-inducing effects of HET on leukemia cells in vitro have also been reported. ${ }^{13}$ However, before the conduction of in vivo animal trials, further investigation into the antitumor effects of HET against other tumor cells is required to clarify the effective extension and strength as well as the mechanisms of apoptotic induction by HET.
Nanomedicine is a division of nanotechnology in which the performance of nanoparticles is applied to medicine and health care areas. One of its essential medical applications is to drug delivery system. The size of nanostructured materials ranged from 1 to $100 \mathrm{~nm}$, and these nanovehicles have high loading capacity and specific targeting to tumor cells due to their size effect and intracellular uptake. ${ }^{14,15}$ Particularly, lipid-based liposomes, micelles, emulsions, as well as biopolymeric nanoparticles, such as nanosized hyaluronan (HA), chitosan (CHI) and gelatin (GEL), with advantageous biocompatible and biodegradable features are specifically selected as carriers in the drug delivery system. In addition to enhanced permeability and retention effect exerted by nanoparticles, the biodegradable nanoparticles provide increased biocompatibility, great drug/vaccine encapsulation, and convenient release profiles for numerous drugs, vaccines, or biomolecules in the biomedical applications. ${ }^{14-17}$ Specific metal like copper oxide and gold nanoparticles themselves have been revealed to have apoptosis-inducing effects on hepatocarcinoma cells and nasopharyngeal carcinoma cells, respectively, implicating antitumor and/or apoptosis-inducing activities possessed by certain nanoparticles. ${ }^{18,19}$ Aggregation/ encapsulation of nanoparticles, including HA, CHI, and GEL, was able to enhance antitumor effects of potential compounds and drugs. ${ }^{20,21} \mathrm{HA}$ is an anionic, nonsulfated, water-soluble polysaccharide, and it is essential for cellular functions. As a drug delivery carrier, HA has numerous functional groups obtainable for conjugation. ${ }^{22}$ On the other hand, the natural cationic polymer $\mathrm{CHI}$ has been shown to have absorption enhancer properties through mucosa, controlled drug release, and bioadhesion. ${ }^{21} \mathrm{CHI}$ has also been found to enhance the cytotoxicity and apoptotic induction of chemotherapeutic agent oxaliplatin via mitochondrial-associated pathways. ${ }^{23}$ We have previously fabricated the biopolymeric nanoparticles using an electrostatic field system (EFS) in an aqueous-phase environment as the drugs/compounds with antitumor activities have been successfully aggregated by the biopolymeric nanoparticles in the EFS. ${ }^{16,17}$ In this study, the natural marine compound HET extracted from a sponge Hippospongia sp. was aggregated by biopolymeric HA and CHI nanoparticles using the EFS method. The antitumor and apoptosis-inducing effects of pure HET and aggregated HET were further investigated and examined using 3-(4,5dimethylthiazol-2-yl)-2,5-diphenyltetrazolium bromide (MTT) assay, migration assay, flow cytometric analysis, and Western blot analysis in vitro. The results revealed in the current study are crucial and promising for following antibladder cancer trials using animal model and are helpful for 
extensive evaluation of pure and nano-HA/CHI-aggregated HET as potentially accessible antiurothelial bladder cancer therapeutic agents.

\section{Materials and methods Materials}

The antibodies against procaspase-3, procaspae-9, procaspase-8, Bax, Bad, Bcl-xL and Bcl-2, apoptosisinducing factor (AIF), poly(ADP-ribose) polymerase-1 (PARP-1) and C/EBP homologous protein (CHOP) were acquired from Cell Signaling Technology (Danvers, MA, USA). The antibodies against eukaryotic translation initiation factor 2 alpha (eIF2 $\alpha$ ), phospho-eIF2 $\alpha$, activating transcription factor 4 (ATF4), phospho-protein kinase RNA-like endoplasmic reticulum kinase (p-PERK), and inositol-requiring enzyme 1 alpha (IRE1 $\alpha$ ) were from Santa Cruz Biotechnology Inc. (Dallas, TX, USA). The antibodies against cleaved caspase-3, cleaved caspase-9, and $\beta$-actin were from EMD Millipore (Bellerica, MA, USA). The antibodies against activating transcription factor 6 (ATF6) alpha were from Abcam (Cambridge, MA, USA). The antibodies against cytochrome $c$ (cyt $c$ ) were from Proteintech Group (Chicago, IL, USA). The secondary horseradish peroxidase-conjugated IgG was from GeneTex (Irvine, CA, USA). Protease inhibitor cocktail was obtained from SigmaAldrich Co. (St Louis, MO, USA). Polyvinylidene difluoride membranes and Chemiluminescent horseradish peroxidase substrate were purchased from Thermo Fisher Scientific (Waltham, MA, USA).

\section{Extraction of HET from the sponge Hippospongia sp.}

The original sponge specimen of Hippospongia sp. was acquired by scuba diving at coral reefs off the coast at Taitung County in Taiwan. Voucher specimen was then deposited in the National Museum of Marine Biology and Aquarium, Taiwan (specimen no 2011SP-1). ${ }^{12}$ The frozen bodies of Hippospongia sp. were collected and freeze-dried. HET was extracted and separated from the sponge Hippospongia sp. as previously described. ${ }^{12}$ Briefly, the freeze-dried minces were exhaustively extracted with ethyl acetate (EtOAc) and then chromatographed through silica gel columns and eluted with EtOAc in $n$-hexane, followed by acetone in EtOAc to produce 13 fractions. Fraction 6 was eluted with $n$-hexaneEtOAc (3:1) and further separated by silica gel column chromatography with gradient elution ( $n$-hexane-EtOAc, $3: 1-1: 1)$ to obtain the compound HET. ${ }^{12}$

\section{Fabrication of $\mathrm{HA}$ and $\mathrm{CHI}$ nanoparticles and aggregation of HET by the nanoparticles}

Biopolymeric nanoparticles of HA and $\mathrm{CHI}$ were prepared as shown previously. In brief, an EFS was created using two parallel copper plates $(18 \mathrm{~cm} \times 6 \mathrm{~cm})$ at a distance of $2 \mathrm{~cm}$ apart. The electric field strength between the plates was provided by a direct current power supply, and a functional generator was used to control the strength. The EFS was constructed in a thermal chamber for temperature control and safety purposes. A stock solution of $25 \mathrm{mg} / \mathrm{mL}$ was prepared by dissolving HET in dimethyl sulfoxide (DMSO). One milliliter of HA or CHI solution $(0.2 \mathrm{mg} / \mathrm{mL})$ was carefully mixed with different amounts of HET. The mixture was transferred onto a petri dish and placed at the center between the two plate electrodes. The main conditions of HA/CHI nanoparticle fabrication for aggregation of HET in the EFS are set as follows: temperature $\left(25^{\circ} \mathrm{C}\right)$, applied electric field strength $(2.5 \mathrm{kV} / \mathrm{cm})$, reaction time (HA: 1 hour, CHI: 5 hours), and cross-linking reagents (HA: $\left.0.001 \mathrm{~N} \mathrm{FeCl}_{3}, \mathrm{CHI}: 0.001 \mathrm{~N} \mathrm{NaOH}\right){ }^{16,17}$ The transmission electron microscopy (TEM) images of HA/CHI nanoparticles, HA/HET, and CHI/HET aggregates are shown in Figure 1.

\section{In vitro release study}

The release of HET $(0.1 \mu \mathrm{g} / \mathrm{mL})$ from HA nanoparticle aggregates was assessed using the method similar to that described previously. ${ }^{17}$ Briefly, HET was added to a centrifuge tube and then placed on a $40 \mathrm{rpm}$ shaker at $37^{\circ} \mathrm{C}$. The sample was centrifuged at 12,000 rpm for 60 minutes before the supernatant was used to determine the amount of HET by high-performance liquid chromatography (Agilent 1100 series; Agilent, Santa Clara, CA, USA). The release of HET from HA nanoparticle aggregates was measured using the following formula: In vitro release $(\%)=[($ total amount of HET - residue of HET)/total amount of HET] $\times 100 \%$.

\section{Cell culture}

T24 Bladder carcinoma cells (derived from ATCC; ATCC number: HTB-4) were acquired from the Bioresource Collection and Research Center (BCRC, Hsinchu, Taiwan). ATCC guidelines were followed to maintain the cell line. In brief, cell culture procedures were conducted in a biohazard laminar flow hood. Sterile equipment and aseptic techniques were executed to prevent contamination. The cells were cultured in McCoy's 5A medium containing 10\% FBS. Cells were grown in a humidified incubator with $5 \% \mathrm{CO}_{2}$ at $37^{\circ} \mathrm{C}$. The culture medium was renewed three times a week. When cells reached $80 \%$ confluence, subculture was performed at a split ratio of 

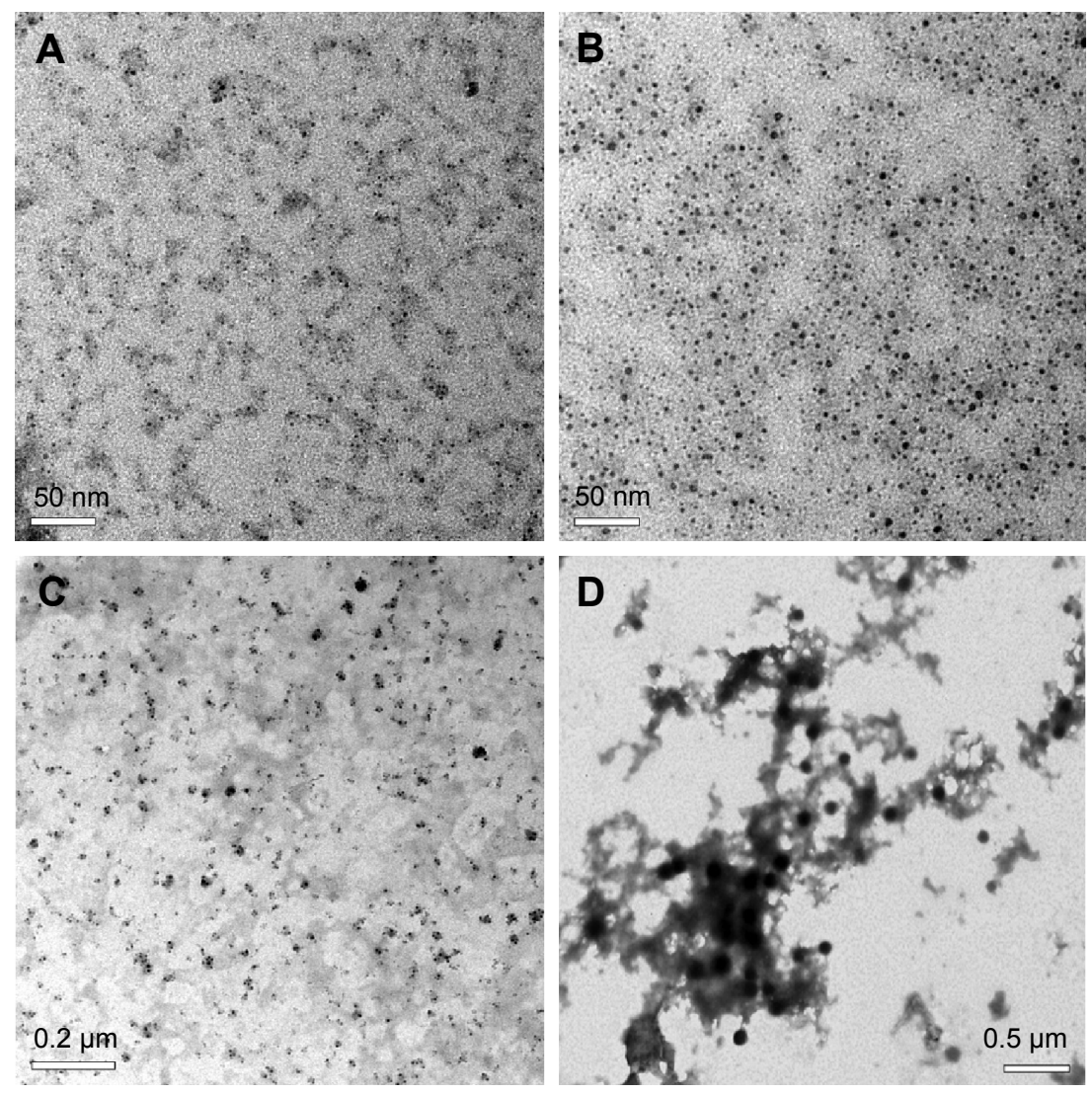

Figure I TEM images of HA (A) and CHI (B) nanoparticles and the aggregates of HA nanoparticles and HET (C) as well as the aggregates of CHI nanoparticles and HET (D). Abbreviations: TEM, transmission electron microscopy; HA, hyaluronan; $\mathrm{CHI}$, chitosan; HET, heteronemin.

$1: 6$ using $0.25 \%$ trypsin. T24 cells were exposed to different concentrations of pure or $\mathrm{HA} / \mathrm{CHI}$ nanoparticles-aggregated HET and harvested after incubation for 24 hours.

\section{Cytotoxic effects of HET, HA/CHI} nanoparticles, and $\mathrm{HA} / \mathrm{CHI}$ nanoparticlesaggregated HET on normal fibroblasts

The cytotoxicity of HA/CHI nanoparticles, pure HET, and HA/CHI nanoparticles-aggregated HET on L929 normal fibroblasts was assessed by MTT assay. The cells $\left(1 \times 10^{4}\right.$ cells/well $)$ were seeded in a 96 -well plate for 24 hours and then treated with various concentrations of HET, HA/CHI nanoparticles, and HA/CHI nanoparticles-aggregated HET. After 24 hours of treatment, $20 \mu \mathrm{L}$ of MTT solution $(5 \mathrm{mg} / \mathrm{mL})$ was added to the cells and additional 4 hours of incubation was followed. The formazan precipitate was dissolved in DMSO, and the absorbance was read on a multiplate reader at $570 \mathrm{~nm}$.

\section{Assessment of cytotoxicity of pure and} $\mathrm{HA} / \mathrm{CHI}$ nanoparticles-aggregated HET against bladder carcinoma cells

The antiviability effects of pure and HA/CHI nanoparticlesaggregated HET on bladder carcinoma cells were examined by MTT assay. Cells at a concentration of 5,000 cells $/ \mathrm{mL}$ were incubated in 96-well plates. Different concentrations of pure HET, HA/HET, and CHI/HET aggregates $(0.1-0.8 \mu \mathrm{g} / \mathrm{mL})$ were prepared and added to each well in triplicate and incubated for 24 hours. To accomplish solubility of MTT formazan crystals in viable cells, $200 \mu \mathrm{L}$ of DMSO was applied to each well followed by vigorous mix. The optimal density was detected at $570 \mathrm{~nm}$ on a multiplate reader while DMSO was used as the blank.

\section{Cell migration assay}

For cell migration assay, T24 bladder carcinoma cells in serum-free media were seeded onto polycarbonate membranes $(8.0 \mu \mathrm{m}$ pore size; BD Biosciences, San Jose, CA, USA) in the culture inserts. Chemoattractant $(10 \%$ fetal bovine serum in McCoy's 5A medium) was added to the lower wells of the plate. The cells were incubated with vehicle, pure HET, HA/HET, or CHI/HET aggregates in the inserts to allow cells to migrate for 24 hours. Nonmigratory cells in the interior of inserts were removed, and migratory cells were fixed and stained using $100 \%$ methanol and Giemsa (EMD Millipore, Billerica, MA, USA), respectively. Migratory bladder cancer cells in three microscopic fields 
at $\times 400$ magnification for each well were counted. The experiment was performed in triplicate. ${ }^{9,24}$

\section{Flow cytometric analysis}

Apoptosis and cell cycle distribution of pure HET- or HA/ HET or CHI/HET aggregates-treated T24 bladder carcinoma cells were quantitated using a flow cytometer (BD LSR II; BD Biosciences). The cells were exposed to various treatments for 24 hours. The apoptosis induced by pure HET, HA/ $\mathrm{HET}$, or $\mathrm{CHI} / \mathrm{HET}$ aggregates was determined by staining with an FITC-conjugated annexin $\mathrm{V}$ propidium iodide (PI) (annexin-V-FITC/PI) kit (Strong Biotech Corp., Taipei, Taiwan) according to the manufacturer's instructions. In brief, the cells were trypsinized from the culture flask and washed three times with PBS. The cell pellets were suspended in $1 \times$ binding buffer and then stained with $5 \mu \mathrm{L}$ of annexin V-FITC and $10 \mu \mathrm{L}$ of PI for 15 minutes.

\section{JC-I staining}

The alterations in the mitochondrial membrane potential $\left(\Delta \Psi_{\mathrm{m}}\right)$ in T24 cells following exposure of various concentrations of pure HET and HA/CHI nanoparticles-aggregated HET were determined by a cyanine JC- 1 dye, which is able to selectively get into mitochondria and changes color from green to red when the potential elevates. Before flow cytometric analysis, JC-1 reagent solution was added to each group after 24 hours of exposure to the treatments and incubated in the dark at $37^{\circ} \mathrm{C}$ for 20 minutes. On a flow cytometer (BD Biosciences), healthy T24 cells containing mitochondria with red JC-1 aggregates can be detected in FL2 channel, whereas green JC-1 monomers in apoptotic T24 cells are captured in FITC channel (FL1).

\section{Western blot analysis}

Western blot analysis was performed based on the methods previously reported. ${ }^{2,9,24}$ The concentrations of protein were determined by bicinchoninic acid assay according to the manufacturer's instructions. In all, 10\% sodium dodecyl sulfate-polyacrylamide gel electrophoresis was used to run and separate the protein samples. Polyvinylidene difluoride membrane was prewetted in methanol for a few seconds and then in transfer buffer for 30 minutes. The proteins of the samples were transferred and blotted onto the membrane. The membranes were incubated in 5\% skim milk powder in Tris-buffered saline with $0.05 \%$ Tween 20 for 1.5 hours at room temperature to block nonspecific protein binding. The membrane was then incubated with primary antihuman antibodies of apoptotic factors, including procaspase-3, cleaved caspase-3, procaspase-9, cleaved caspase-9, procaspase-8, cyt $c$, Bax, Bad, Bcl-xL, Bcl-2, PARP-1, AIF, eIF2 $\alpha$, p-eIF2 $\alpha$, IRE1 $\alpha$, p-PERK, CHOP, ATF4, cleaved-ATF6, and $\beta$-actin overnight at $4^{\circ} \mathrm{C}$.

\section{Statistical analysis}

Experimental data were pooled from at least three independent tests. Data of MTT assay, cell migration assay, and flow cytometric analysis are presented as mean \pm standard error of mean. Unless otherwise indicated, analysis of variance was followed by the Tukey-Kramer test to determine the existence of significant differences $(P \leq 0.05)$ between experimental groups using a GraphPad InStat 3 software (GraphPad Software, Inc., La Jolla, CA, USA). ${ }^{9,24}$

\section{Results}

\section{Observations of $\mathrm{HA} / \mathrm{CHI}$ nanoparticles and $\mathrm{HA} / \mathrm{HET}$ and $\mathrm{CHI} / \mathrm{HET}$ aggregates by TEM}

The TEM images of HA/CHI nanoparticles and HA/HET and $\mathrm{CHI} / \mathrm{HET}$ aggregates prepared in this study are shown in Figure 1. The size of the well-dispersed and spherical HA nanoparticles prepared by the EFS was $\sim 2.9 \pm 0.8 \mathrm{~nm}$ in diameter. The $\mathrm{CHI}$ nanoparticles also presented round shape with a mean diameter of $\sim 4.6 \pm 1.5 \mathrm{~nm}$. HET encapsulated by HA (HA/HET aggregates) presented with somewhat irregular shape with an average diameter of $25.6 \pm 8.5 \mathrm{~nm}$ using electron microscopy. The mean diameter of $\mathrm{CHI} / \mathrm{HET}$ aggregates is larger $(81.8 \pm 13.0 \mathrm{~nm})$, and the aggregates showed more consistent shape compared with that of HA/HET aggregates.

\section{In vitro release of HET from HA nanoparticle aggregates}

The release profile of HET $(0.1 \mu \mathrm{g} / \mathrm{mL})$ from HA nanoparticle aggregates is shown in Figure 2. An initial burst release of HET at the first hour was $\sim 26 \%$. The release pattern of HET from HA nanoparticle aggregates presented with a relatively rapid and steady pattern from 0 to 6 hours. HET released from HA nanoparticle aggregates reached to $\sim 73 \%$ after 6 hours, and the release was $\sim 90 \%$ after 24 hours of incubation.

\section{Effects of HET, HA/CHI nanoparticles, and $\mathrm{HA} / \mathrm{CHI}$ nanoparticles-aggregated HET on normal fibroblast viability}

The effects of HA/CHI nanoparticles, pure HET, and HA/ CHI nanoparticles-aggregated HET on L929 normal fibroblast viability were examined by MTT assay (Figure 3). Pure HET from 0.1 to $0.4 \mu \mathrm{g} / \mathrm{mL}$ showed slight but not significant decrease in $\mathrm{L} 929$ cell viability. Either HA or CHI 


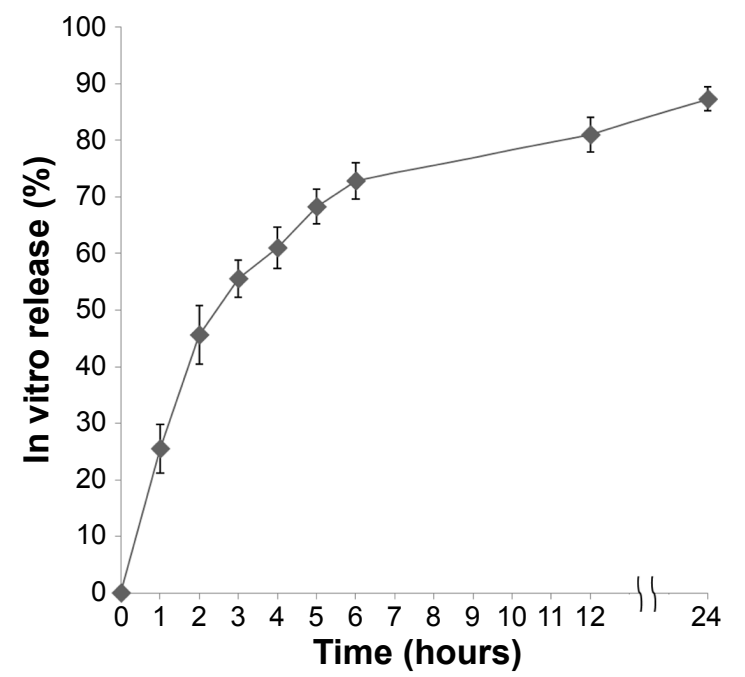

Figure 2 In vitro release profile of HET from HA nanoparticle aggregates $(\mathrm{N}=3)$. Abbreviations: HET, heteronemin; HA, hyaluronan.

nanoparticles at concentrations between 0.1 and $20 \mathrm{mg} / \mathrm{mL}$ did not exhibit significant inhibitory effects on L929 cell viability. HA nanoparticles-aggregated HET at $0.1,0.2$, and $0.4 \mu \mathrm{g} / \mathrm{mL}$ showed $<10 \%$ inhibitory effects on L929 cell viability, and viability-suppressed effects of all these HETs at $0.1-0.4 \mu \mathrm{g} / \mathrm{mL}$-loaded HA on normal fibroblasts were $<0.2 \mu \mathrm{g} / \mathrm{mL}$ pure HET, indicating lower toxicity of HET after HA nanoparticle aggregation.

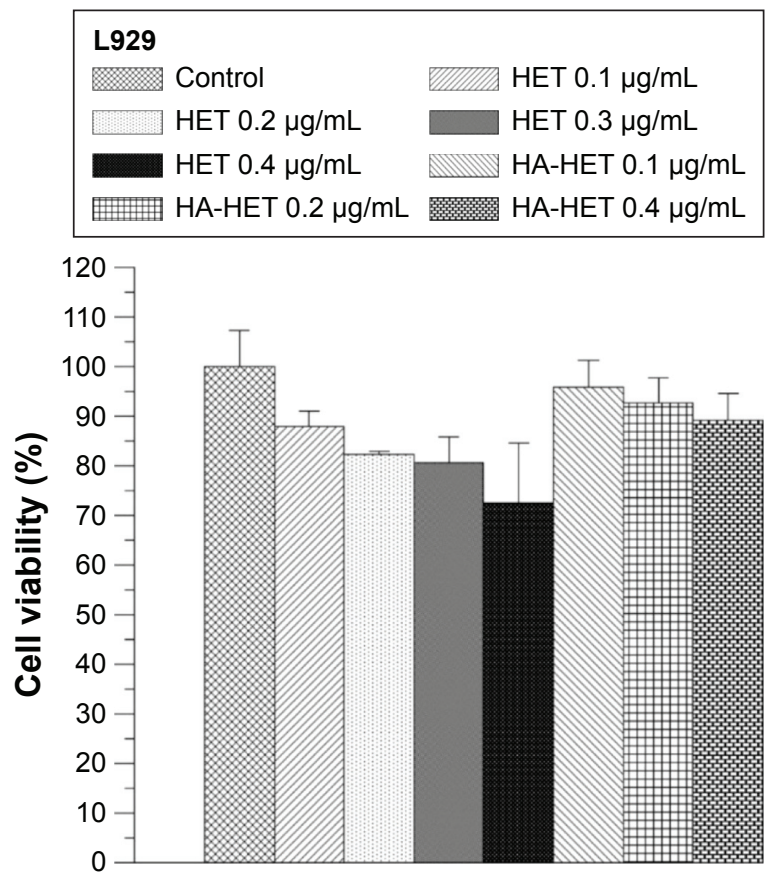

Figure 3 Effects of HET and HA/HET aggregates on viability of L929 normal fibroblasts.

Note: HET from 0.1 to $0.4 \mu \mathrm{g} / \mathrm{mL}$ as well as $0.1,0.2$, and $0.4 \mu \mathrm{g} / \mathrm{mL} \mathrm{HA}$ nanoparticles-aggregated HET did not show significant cytotoxic effects on L929 normal fibroblasts $(\mathrm{N}=3)$.

Abbreviations: HET, heteronemin; HA, hyaluronan.

\section{Cytotoxic effects of HET and HA/CHI nanoparticles-aggregated HET against bladder carcinoma cells}

The cytotoxic effects of pure and HA/CHI nanoparticlesaggregated HET against T24 bladder carcinoma cells were assessed by MTT assay (Figure 4). Pure HET from 0.2 to $0.8 \mu \mathrm{g} / \mathrm{mL}$ significantly reduced $\mathrm{T} 24$ cell viability, and the $\mathrm{IC}_{50}$ toward the cells was $\sim 0.28 \mu \mathrm{g} / \mathrm{mL}$. Pure HET at $0.1 \mu \mathrm{g} / \mathrm{mL}$ did not have any clear cytotoxic effects on bladder cancer cells. The HA nanoparticles-aggregated HET at $0.1 \mu \mathrm{g} / \mathrm{mL}$ significantly suppressed T24 cell viability, indicating that HA nanoparticle aggregation can efficiently enhance the cytotoxic effects of pure HET at low concentration showing no cytotoxic effects on bladder carcinoma cells. In addition, $0.2 \mu \mathrm{g} / \mathrm{mL}$ HET-loaded HA nanoparticles showed slightly higher inhibitory effects on T24 cell viability.

\section{Assessment of antimigratory effects exerted by $\mathrm{HET}$ and $\mathrm{HA} / \mathrm{CHI}$ nanoparticles-aggregated HET}

The antimigratory effects of pure HET and HA/CHI nanoparticles-aggregated HET were determined by migration assay (Figure 5). Pure HET at $0.2-0.8 \mu \mathrm{g} / \mathrm{mL}$ significantly suppressed the migration of T24 bladder carcinoma cells.

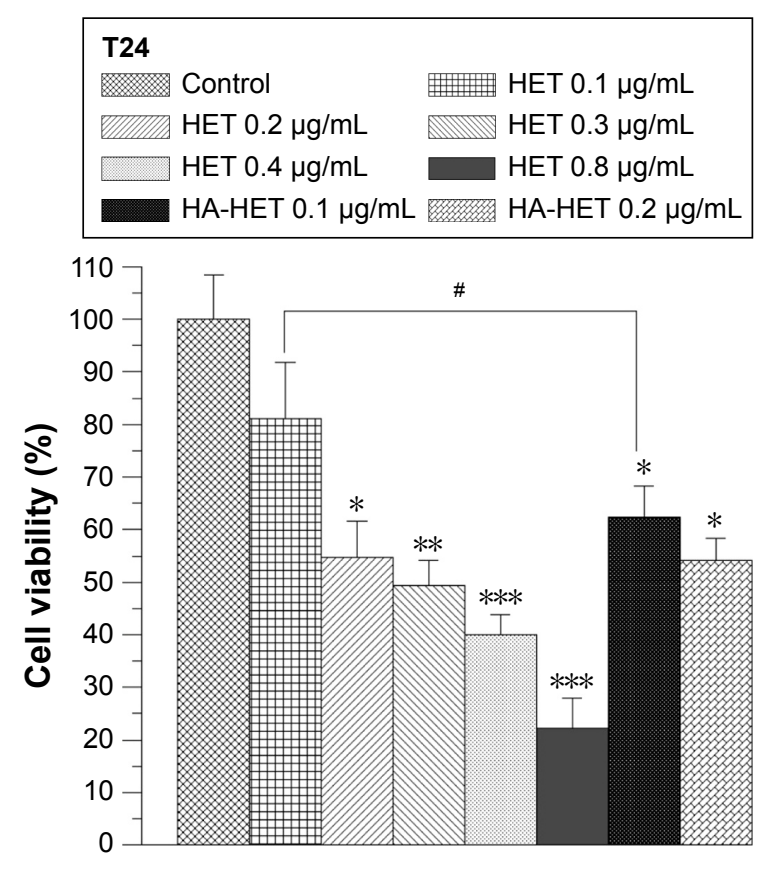

Figure 4 Cytotoxic effects of pure HET and HA/HET aggregates against T24 bladder carcinoma cells.

Note: Pure HET at $0.2-0.8 \mu \mathrm{g} / \mathrm{mL}$ displayed significant inhibitory actions on bladder carcinoma cell viability as 0.1 and $0.2 \mu \mathrm{g} / \mathrm{mL} \mathrm{HA}$ nanoparticles-aggregated HET showed significant cytotoxic effects against the bladder carcinoma cells (* and ${ }^{*} P<0.05$, **P $<0.01$, **** $P<0.00$ I; $\mathrm{N}=5$ ).

Abbreviations: HET, heteronemin; HA, hyaluronan. 
Meanwhile, CHI nanoparticles themselves exerted antimigratory activities on $\mathrm{T} 24$ cells. HA nanoparticles-aggregated HET from 0.1 to $0.4 \mu \mathrm{g} / \mathrm{mL}$ and CHI-aggregated HET at 0.2 and $0.4 \mu \mathrm{g} / \mathrm{mL}$ possessed much stronger migrationinhibitory effects than pure HET at the same concentrations, suggesting that both $\mathrm{HA}$ and $\mathrm{CHI}$ nanoparticle aggregations accelerate antimigratory effects of HET against bladder carcinoma cells in vitro.
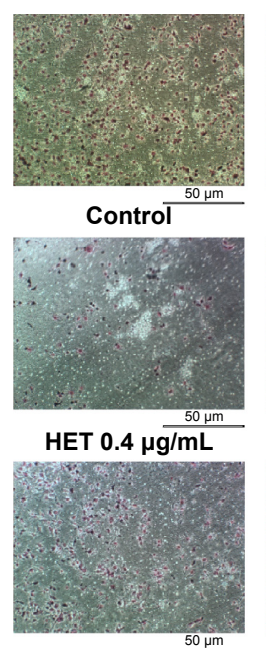

HA

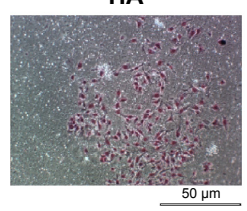

CHI $\stackrel{50 \mu \mathrm{m}}{ }$

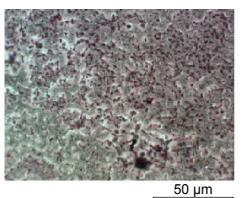

HET $0.1 \mu \frac{50 \mathrm{~mm}}{\mu \mathrm{gL}}$

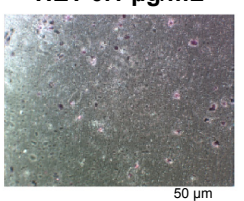

HET $0.6 \mu \frac{50 \mathrm{Hm}}{\mu \mathrm{mL}}$

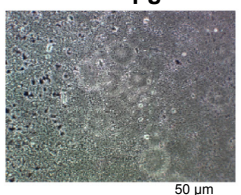

HA-HET $0.1 \mu \mathrm{gg} / \mathrm{mL}$

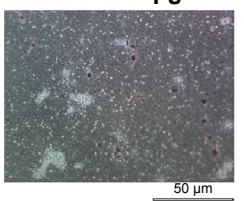

CHI-HET $0.2 \frac{50 \mu m}{\mu \mathrm{gg} / \mathrm{mL}}$

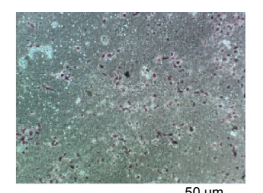

HET $0.2 \mu \frac{50 \mu \mathrm{mm}}{\mu \mathrm{mL}}$

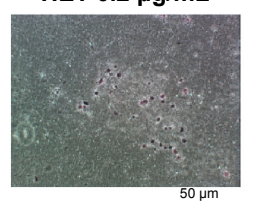

Het $0.8 \mu \mathrm{g} / \mathrm{mL}$

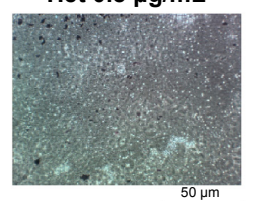

HA-HET $0.2 \mu \mathrm{\mu g} / \mathrm{mL}$

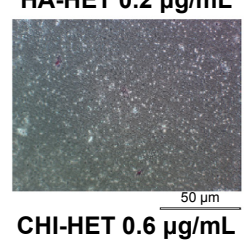

Effects of HET and HA/CHI

nanoparticles-aggregated HET on apoptotic induction and cell cycle distribution by flow cytometric analysis

The apoptosis-inducing effects of pure and HA/CHI nanoparticles-aggregated HET on bladder carcinoma cells were examined by annexin V-FITC and PI staining on a flow cytometer (Figure 6). Early apoptosis rate in

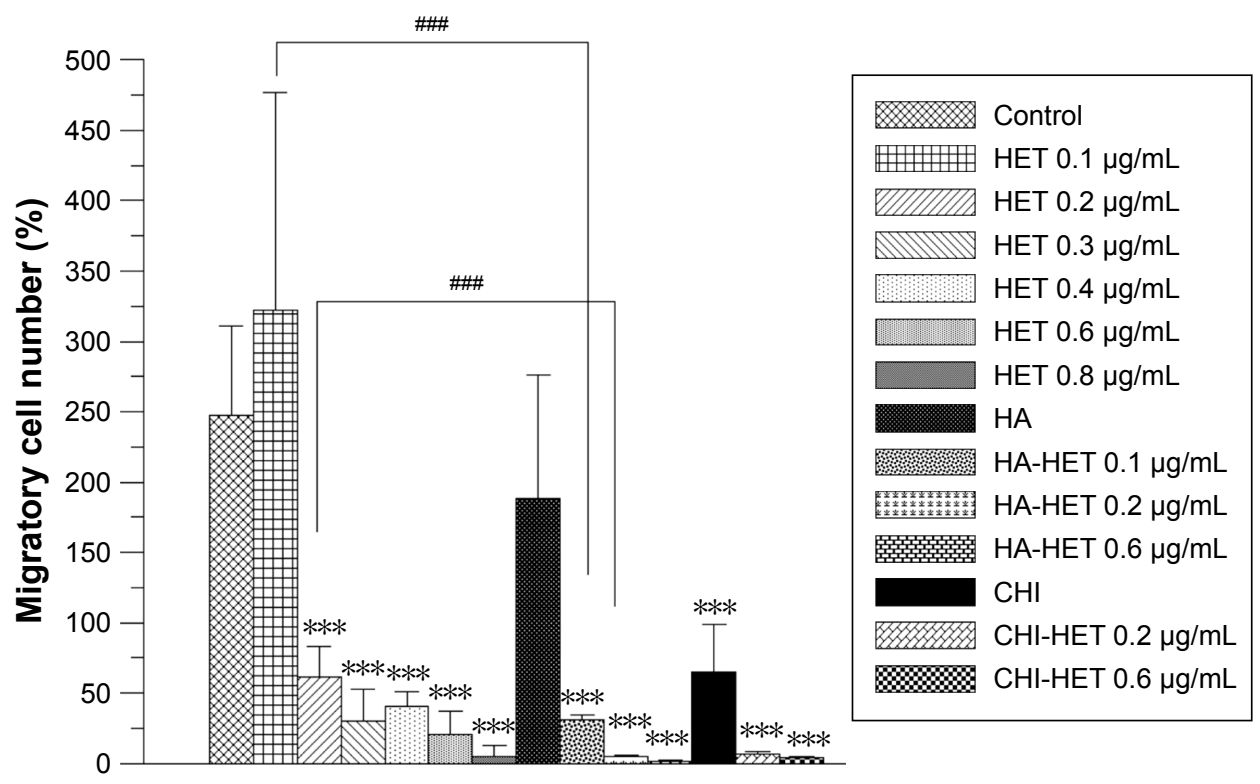

Figure 5 Antimigratory effects of pure HET, HA/HET aggregates, $\mathrm{CHI}$ nanoparticles, and $\mathrm{CHI} / \mathrm{HET}$ aggregates against bladder carcinoma cells.

Note: Except for $0.1 \mu \mathrm{g} / \mathrm{mL}$ pure HET and HA nanoparticles themselves, pure HET from 0.2 to $0.8 \mu \mathrm{g} / \mathrm{mL}$, HA nanoparticles-aggregated HET at $0.1-0.6 \mu g / \mathrm{mL}$, and $\mathrm{CHI}$ nanoparticles and $\mathrm{CHI}$ nanoparticles-aggregated $\mathrm{HET}$ at 0.2 and $0.6 \mu \mathrm{g} / \mathrm{mL}$ exhibited significantly suppressed effects on bladder carcinoma cell migration $\left(* * *\right.$ and ${ }^{\prime \prime} P<0.00 \mathrm{I}$; $\mathrm{N}=3$ ).

Abbreviations: $\mathrm{HET}$, heteronemin; $\mathrm{HA}$, hyaluronan; $\mathrm{CHI}$, chitosan. 

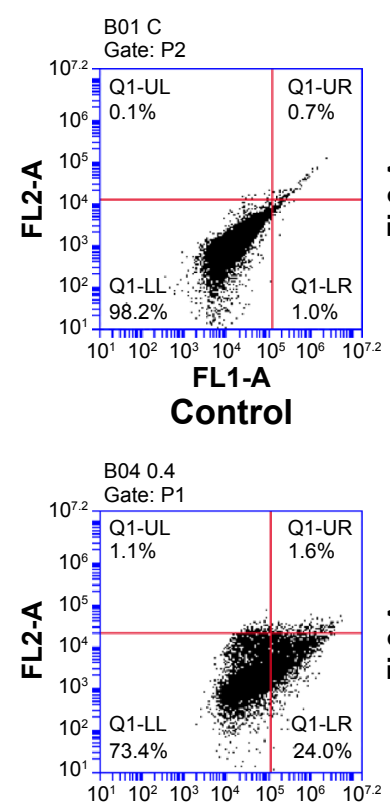

FL1-A

HET $0.4 \mu \mathrm{g} / \mathrm{mL}$

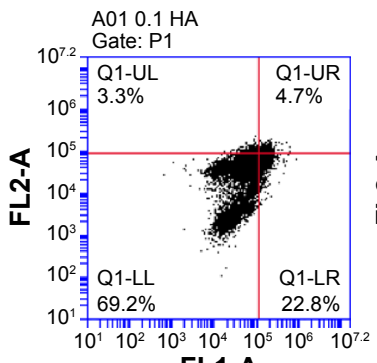

FL1-A

HA-HET $0.1 \mu \mathrm{g} / \mathrm{mL}$

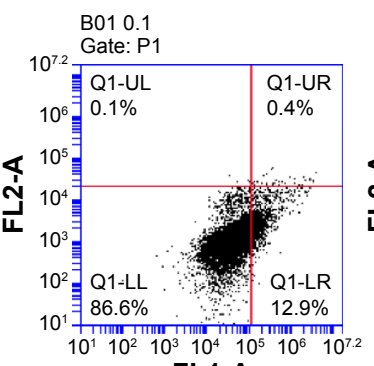

FL1-A

HET $0.1 \mu \mathrm{g} / \mathrm{mL}$

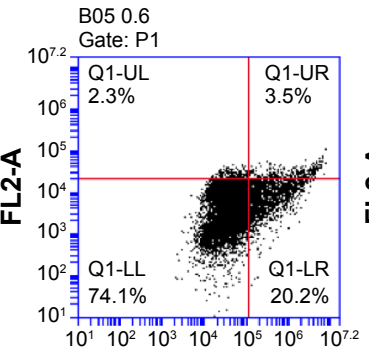

FL1-A

HET $0.6 \mu \mathrm{g} / \mathrm{mL}$

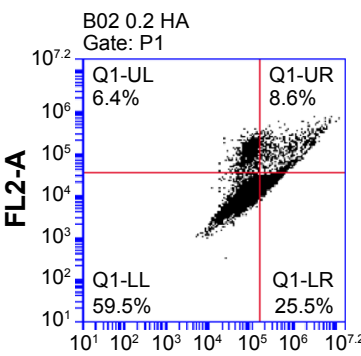

FL1-A

HA-HET $0.2 \mu \mathrm{g} / \mathrm{mL}$

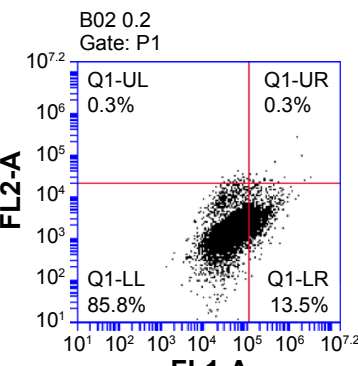

FL1-A

HET $0.2 \mu \mathrm{g} / \mathrm{mL}$

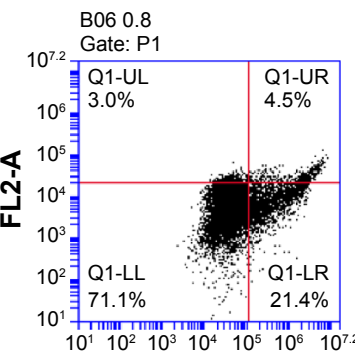

FL1-A

HET $0.8 \mu \mathrm{g} / \mathrm{mL}$

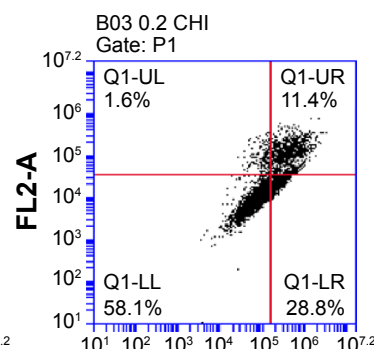

FL1-A

CHI-HET $0.2 \mu \mathrm{g} / \mathrm{mL}$

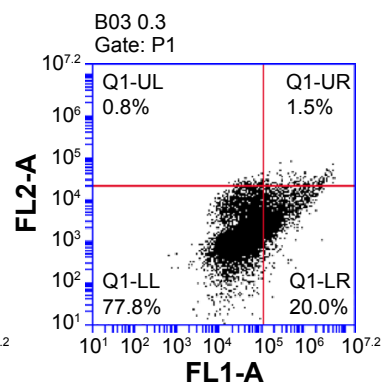

HET $0.3 \mu \mathrm{g} / \mathrm{mL}$
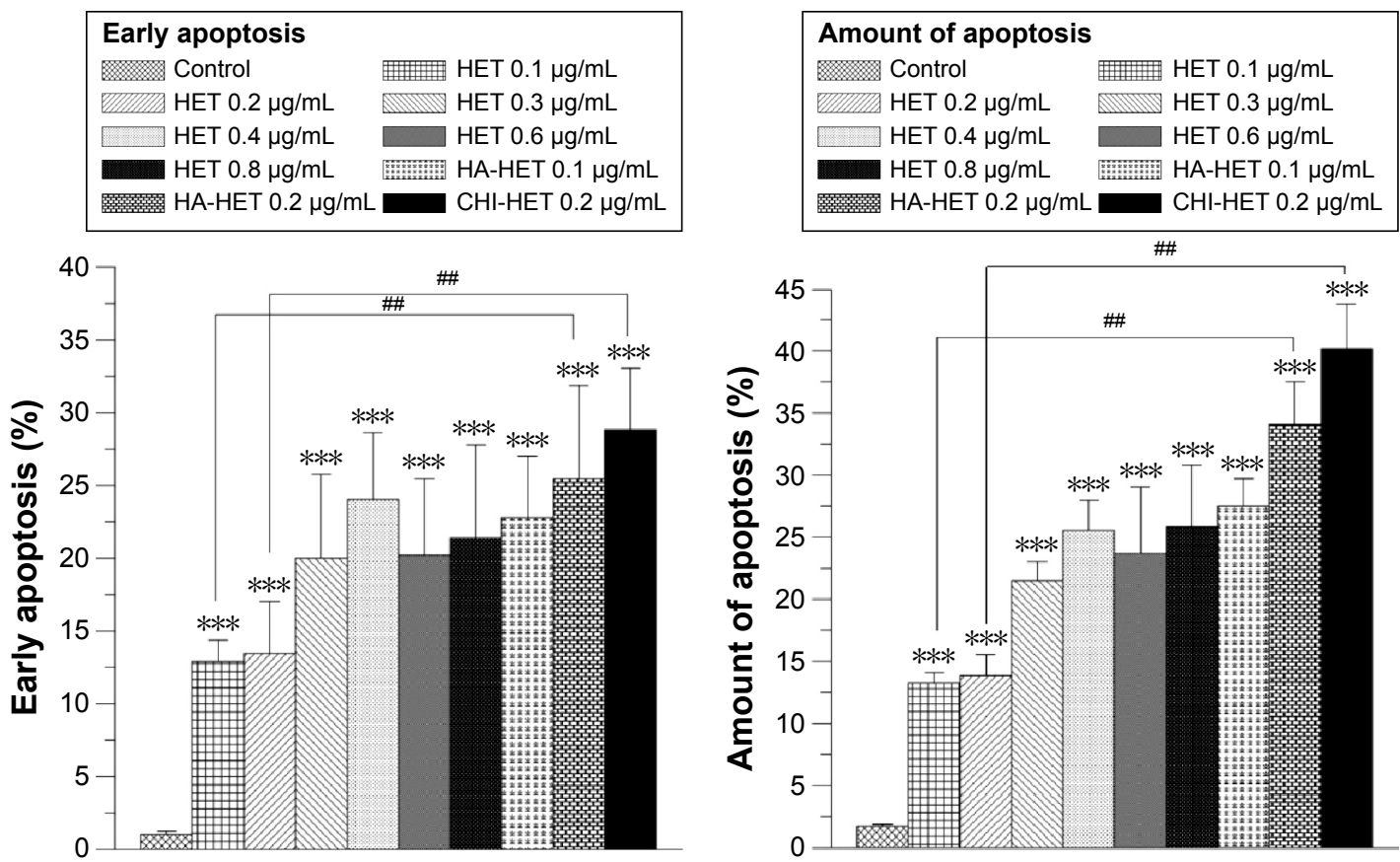

Figure 6 Assessment of apoptosis induced by pure HET, HA/HET, and CHI/HET aggregates by Annexin V/PI staining and flow cytometric analysis.

Note: HA nanoparticles-aggregated HET at 0.1 and $0.2 \mu \mathrm{g} / \mathrm{mL}$ approximately doubled the early apoptosis and total apoptotic rate of T24 bladder carcinoma cells in comparison with those of pure HET at the same concentrations (***P<0.00I, $P<0.01 ; N=3)$.

Abbreviations: HET, heteronemin; HA, hyaluronan; $\mathrm{CHI}$, chitosan; PI, propidium iodide. 
$0.1-0.8 \mu \mathrm{g} / \mathrm{mL}$ pure HET-treated groups was significantly increased compared with that in control. In addition, both HA nanoparticles-aggregated HET $(0.1$ and $0.2 \mu \mathrm{g} / \mathrm{mL})$ and $\mathrm{CHI}$ nanoparticles-aggregated HET $(0.2 \mu \mathrm{g} / \mathrm{mL})$ induced higher early and total apoptosis rate in comparison with pure HET at the identical concentrations. The apoptosis rates induced by nanoparticles-aggregated HET approximately reached or even surpassed the counterparts induced by $0.8 \mu \mathrm{g} / \mathrm{mL}$ pure HET, suggesting that aggregation of HA and $\mathrm{CHI}$ nanoparticles can significantly enhance HET-induced early and total apoptosis in bladder carcinoma cells in vitro. PI staining was also performed to assess the distribution of cell DNA content after exposure to pure or HA nanoparticlesaggregated HET. The ratio of sub-G1 was significantly increased in $0.2-0.4 \mu \mathrm{g} / \mathrm{mL}$ pure HET and $0.2 \mu \mathrm{g} / \mathrm{mL} \mathrm{HA} /$ HET aggregates-treated groups (Figure 7).

\section{JC-I staining}

Loss of mitochondrial membrane potential $(\Delta \psi)$, indicative of apoptosis, can be detected by a unique fluorescent cationic dye JC-1. It has been revealed that mitochondrial depolarization is indicated by a decrease in the red/green fluorescence intensity ratio. ${ }^{25}$ Our results showed that pure HET from 0.1 to $0.4 \mu \mathrm{g} / \mathrm{mL}$ dose-dependently elevated green monomer rate as red aggregate rate gradually reduced with the increasing concentrations of pure HET, resulting in a decrease in red/ green fluorescence. Meanwhile, HA nanoparticles-aggregated HET at $0.1 \mu \mathrm{g} / \mathrm{mL}$ exhibited a larger decrease in $\mathrm{red} / \mathrm{green}$ fluorescence than pure HET, suggesting that aggregation of HA nanoparticles is able to further enhance the amount of green fluorescent JC-1 monomers (1.53 folds) and increase the loss of mitochondrial potential in T24 bladder carcinoma cells (Figure 8).

\section{Western blot analysis}

The pathways of apoptosis induced by pure HET and HA nanoparticles-aggregated HET in bladder carcinoma cells were further validated by Western blot analysis. As shown in Figure 9A, mitochondrial-associated/caspase-dependent apoptotic factors, including cleaved caspase-3, cleaved caspase-9, Bax, Bad and cyt $c$ (cytosol), were increased after 24 hours of treatment with $0.1-0.4 \mu \mathrm{g} / \mathrm{mL}$ pure HET as well as 0.1 and $0.2 \mu \mathrm{g} / \mathrm{mL}$ HA nanoparticles-aggregated HET. HA nanoparticles-aggregated HET at 0.1 and $0.2 \mu \mathrm{g} / \mathrm{mL}$ induced stronger cleaved caspase- 3 and caspase- 9 compared with pure HET at the same concentrations. Antiapoptotic factors such as Bcl-xL, Bcl-2, as well as procaspase-3, procaspase- 9 , and procaspase- 8 were reduced with exposure to increasing concentrations of pure HET and HA nanoparticlesaggregated HET at 0.1 and $0.2 \mu \mathrm{g} / \mathrm{mL}$. Larger decreases of Bcl-xL, Bcl-2, and procaspase- 8 were also observed in 0.1 and $0.2 \mu \mathrm{g} / \mathrm{mL}$ HA nanoparticles-aggregated HET groups in comparison with pure HET at the same concentrations. These results verified that mitochondrial-related, caspasedependent pathways are involved in the apoptosis induced by pure HET and HA nanoparticles-aggregated HET against bladder carcinoma cells (Figure 9A). On the other hand, exposure to pure HET $(0.2-0.4 \mu \mathrm{g} / \mathrm{mL})$ as well as $0.1 \mu \mathrm{g} / \mathrm{mL}$ HA nanoparticles-aggregated HET increased PARP-1, while higher presence of AIF was observed in 0.1 and $0.2 \mu \mathrm{g} / \mathrm{mL}$ HA nanoparticles-aggregated HET groups, implicating that HA nanoparticle aggregation seems to be able to enhance the apoptosis-inducing effects of low-concentration HET on bladder carcinoma cells through caspase-independent pathway (Figure 9B).

Furthermore, increases in p-PERK, p-eIF2 $\alpha$, ATF4, CHOP, and IRE1 $\alpha$ and a decrease in eIF2 $\alpha$ were observed in $0.1-0.4 \mu \mathrm{g} / \mathrm{mL}$ pure HET and, particularly, in 0.1 and $0.2 \mu \mathrm{g} / \mathrm{mL}$ HA nanoparticles-aggregated HET-treated groups, indicating that exposure to both pure and HA nanoparticlesaggregated HET can induce apoptosis in bladder carcinoma cells via several endoplasmic reticulum (ER) stress-associated pathways. HET with HA nanoparticle aggregation at 0.1 and $0.2 \mu \mathrm{g} / \mathrm{mL}$ principally enhanced these ER sensors compared with pure HET at the same concentrations, suggesting that HA nanoparticle aggregation enables reinforcement of apoptotic induction via ER stress-related PERK/eIF2 $\alpha / \mathrm{ATF} 4 /$ CHOP and IRE1 $\alpha /$ CHOP pathways in the carcinoma cells (Figure 9B).

\section{Discussion}

We have previously aggregated potential antitumor compounds, including dihydroartemisinin and curcumin, with biodegradable and biocompatible nanosized HA, CHI, and GEL particles using EFS to successfully reinforce their anticancer activities against non-small cell lung cancer (NSCLC) cells. ${ }^{16,17}$ However, the antitumor activities exerted by marine natural compounds encapsulated by these polymeric nanoparticles against urothelial tumor cells have not been studied. In addition, the preapoptotic and antiapoptotic factors involved in the pathways of the biodegradable nanoparticles-aggregated compound-induced apoptosis have not been extensively investigated. Therefore, the current study examined the antibladder tumor effects and apoptotic pathways of HET extracted from the marine sponge and further investigated the mechanisms of the antitumor effects 

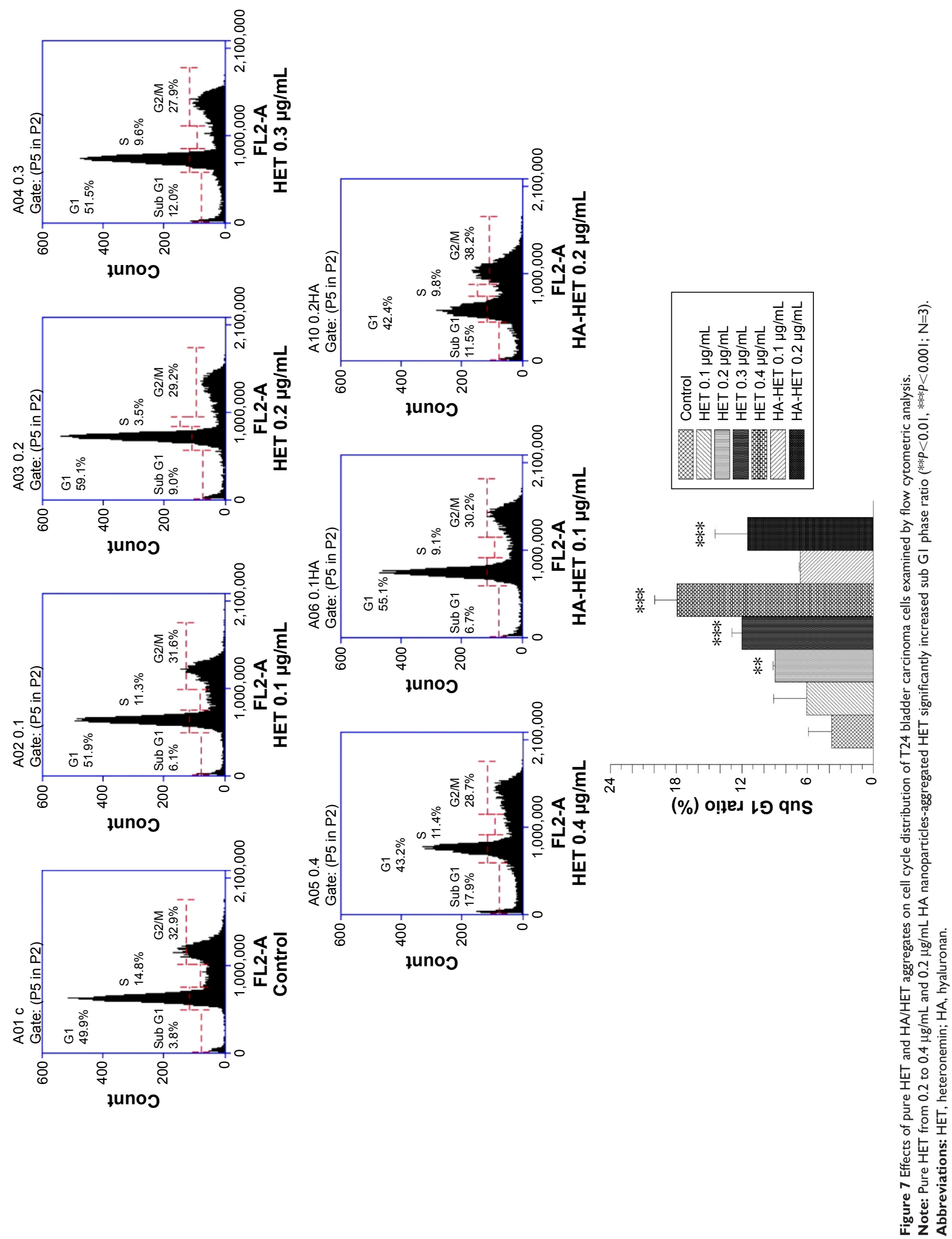

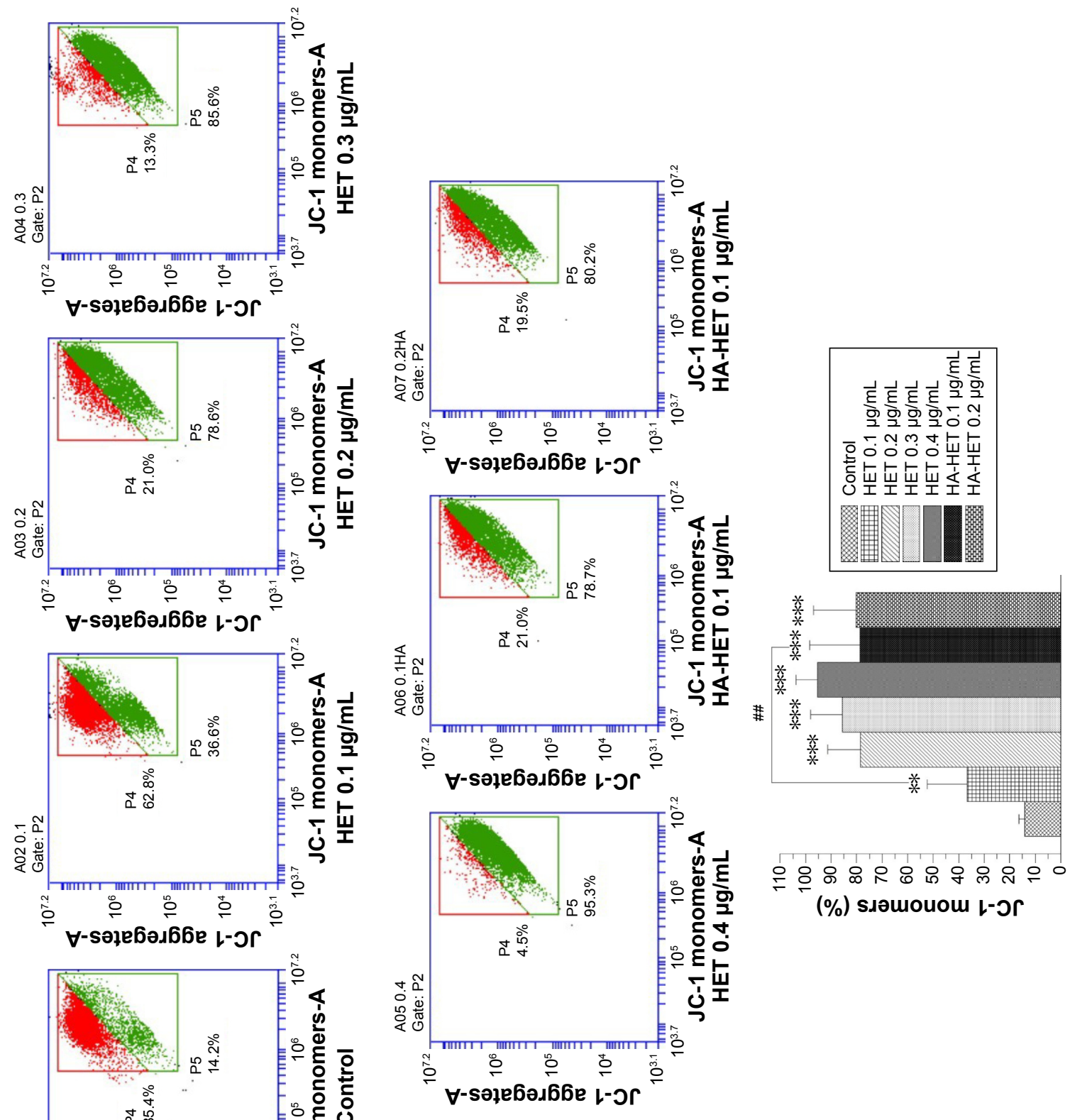

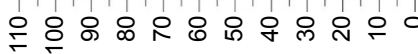

(\%) suəuouou l-כr

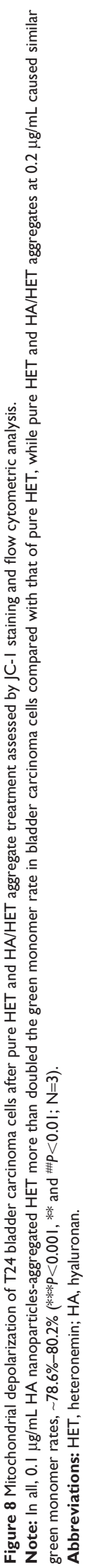



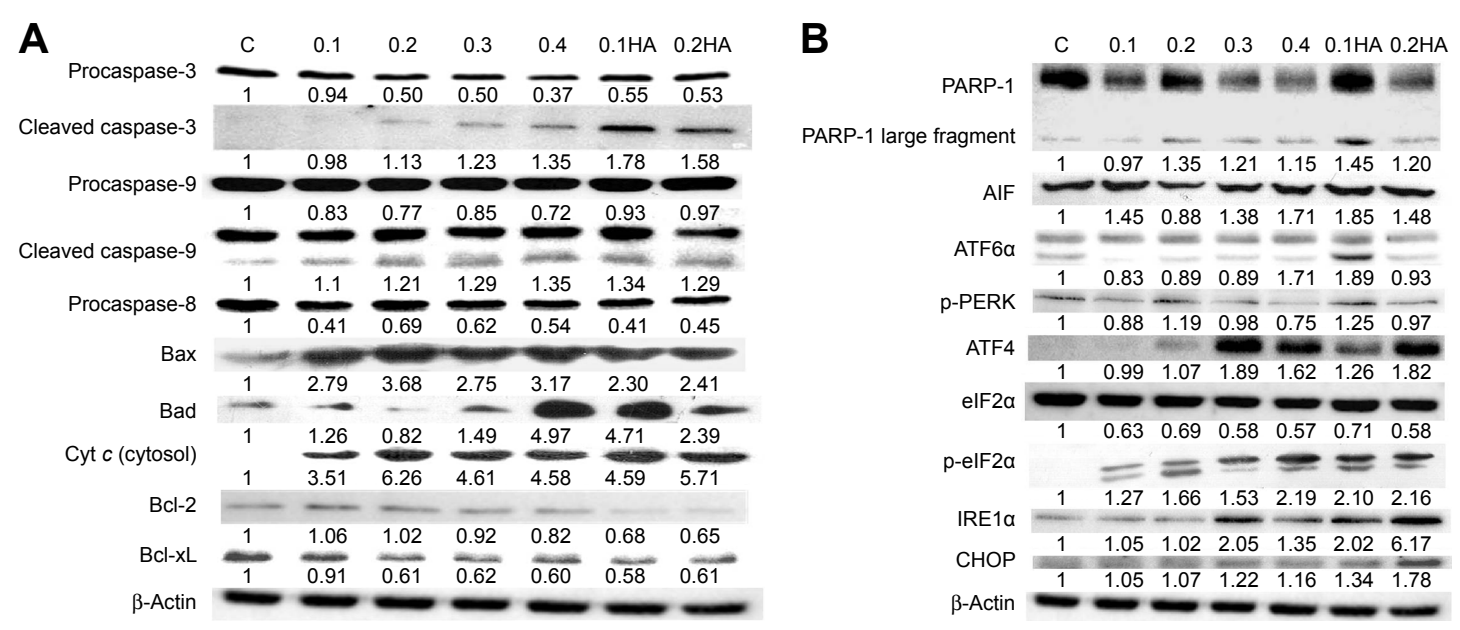

Figure 9 Western blotting analysis of the changes in mitochondrial-related, caspase-dependent factors (A) as well as caspase-independent and ER stress-associated factors (B) in T24 bladder carcinoma cells after 24 hours of exposure to pure HET and HA nanoparticles-aggregated HET.

Note: The blots were quantified using Imagel software (National Institutes of Health, Bethesda, MD, USA). ${ }^{33}$

Abbreviations: ER, endoplasmic reticulum; HET, heteronemin; HA, hyaluronan; Cyt c, cytochrome c; PARP-I, poly(ADP-ribose) polymerase-I; AIF, apoptosis-inducing factor; ATF6 $\alpha$, activating transcription factor 6 alpha; p-PERK, phospho-protein kinase RNA-like endoplasmic reticulum kinase; ATF4, activating transcription factor 4; elF2 $\alpha$, eukaryotic translation initiation factor 2 alpha; p-elF2 $\alpha$, phospho-eukaryotic translation initiation factor 2 alpha; IREI $\alpha$, inositol-requiring enzyme I alpha; CHOP, C/EBP homologous protein.

of HET after HA/CHI nanoparticle aggregation, using MTT assay, migration assay, flow cytometric analysis, JC-1 staining, and Western blot analysis. As a result, the $\mathrm{IC}_{50}$ of pure HET against T24 bladder carcinoma cells was $\sim 0.28 \mu \mathrm{g} / \mathrm{mL}$ as the viability-inhibitory effect of pure HET on cancer cells was $>70 \%$ at $0.4 \mu \mathrm{g} / \mathrm{mL}$, showing potent cytotoxic effects of HET against bladder carcinoma cells in vitro. Notably, HA nanoparticles-aggregated HET presented with stronger and similar viability-inhibitory activities against bladder carcinoma cells at 0.1 and $0.2 \mu \mathrm{g} / \mathrm{mL}$, respectively, in comparison with pure HET at identical concentrations. This is coherent with that 0.1 and $0.2 \mu \mathrm{g} / \mathrm{mL}$ HA nanoparticles-aggregated HET significantly elicited higher early and total apoptosis compared with pure HET at identical concentrations. Meanwhile, $0.1,0.2$, and $0.4 \mu \mathrm{g} / \mathrm{mL}$ HA nanoparticles-aggregated HET caused less cell death in L929 normal fibroblasts compared with pure HET. These data suggested that the aggregation of HA nanoparticles is capable of increasing the cytotoxic and apoptosis-inducing effects of HET and may thus reduce the necrosis-causing effects of HET on T24 bladder carcinoma cells. Meanwhile, the reduction in causing necrosis achieved by HA nanoparticles-aggregated HET could be the reasons for higher viable rate of normal L929 cells. Moreover, natural compound HET was initially limited by its low solubility and bioavailability in cell-culturing environment, but aggregation with HA nanoparticles as a drug carrier showed a steady releasing pattern of HET within 24 hours. The aggregation of biodegraded nanoparticles, such as HA and $\mathrm{CHI}$, has been shown to improve the bioavailability of compounds with poor solubility in water, ${ }^{17}$ which is in accordance with the enhancement and improvement of antitumor effects of HET in vitro in the current study.

The antimigratory effects exerted by pure and $\mathrm{HA} / \mathrm{CHI}$ nanoparticles-aggregated HET were extensively assessed by migration assay in the current study. Pure HET from 0.2 to $0.8 \mu \mathrm{g} / \mathrm{mL}$ significantly suppressed $75 \%$ to $98 \%$ T24 bladder carcinoma cell migration. In addition, $\mathrm{HA} / \mathrm{CHI}$ nanoparticle aggregation more than tenfold enhanced the inhibitory effects of HET at 0.1 and $0.2 \mu \mathrm{g} / \mathrm{mL}$ against the carcinoma cell migration. Similarly, hydrophilic polymeric polyethylene glycol nanoparticles combined with thymoquinone, a major active constituent of black seeds of Nigella sativa, have been found to possess distinct cell migration-retarded effects against breast cancer cells. ${ }^{26}$ Interestingly, our study found that $\mathrm{CHI}$ nanoparticles themselves also retarded T24 cell migration by $\sim 75 \%$, which could partially explain why $\mathrm{CHI}$ nanoparticle aggregation largely strengthens the antimigratory effects of HET on the bladder carcinoma cells. It is noteworthy that gold nanoparticles themselves, particularly gold nanospheres and long gold nanorods with positive potentials, were revealed to have higher capacity to inhibit prostate carcinoma cell migration compared with gold nanoparticles with negative potential. Gold nanoparticles with positive potential were able to increase human dermal fibroblast migration. ${ }^{27}$ Our antimigratory data on pure HET, CHI nanoparticles, and HA/CHI nanoparticles-aggregated HET combined with previous related findings evidently support the proposal that the future in vivo antibladder cancer studies on these polymeric 
biodegraded nanoparticles-aggregated natural compounds are reasonable and promising.

The mitochondrial-associated, caspase-dependent pathways of pure and HA/CHI nanoparticles-aggregated HETinduced apoptosis were examined by $\mathrm{JC}-1$ staining and Western blot analysis. The JC-1 staining results showed that pure HET from 0.2 to $0.6 \mu \mathrm{g} / \mathrm{mL}$ gradually elevated rates of JC-1 monomers (green), which is in accordance with an increase of cyt $c$ into cytosol. These results suggest that loss of mitochondrial membrane potentials is involved in the apoptosis elicited by HET. Furthermore, treatment with HA nanoparticles-aggregated HET at $0.1 \mu \mathrm{g} / \mathrm{mL}$ produced approximately twofold elevation in the $\mathrm{JC}-1$ green monomer rate and AIF presence compared with pure HET. The JC-1, Annexin V/PI staining, and Western blot data demonstrated that HA nanoparticle aggregation is capable of increasing the HET-induced apoptosis and loss of mitochondrial potentials is included in the mechanisms of the enhanced apoptosis. Moreover, decreases of Bcl-xL, Bcl-2, procaspase-9, and procaspase- 8 and increases of Bax, Bad, cyt $c$ (cytosl), cleaved caspase-9, and cleaved caspase- 3 combined with the $\mathrm{JC}-1$ results also showed that the apoptotic pathways induced by pure and HA nanoparticles-aggregated HET are involved with mitochondrial-associated and caspasedependent routes. The caspase-dependent mechanisms of pure HET in the current study are similar with the apoptotic induction of HET shown in leukemia cells. ${ }^{13}$ The previous results together with the data found in our study suggested that HET is able to induce apoptosis in both leukemia and bladder carcinoma cells via caspase-dependent pathways. In addition, Western blot data in our study found that the aggregation of HA nanoparticles can enhance the induction of apoptosis in bladder carcinoma cells via mitochondrialrelated, caspase-independent PARP-1/AIF pathway, whereas pure HET seemed to not principally induce bladder carcinoma cell apoptosis through this pathway.

Other crucial events in addition to the mitochondrialassociated pathways that can result in apoptosis in cancer have been revealed to be relevant with ER stress. ${ }^{28-30}$ Natural compounds extracted from marine soft corals have been shown to display apoptotic effects against tumor cells via the ER stress-related pathways. ${ }^{9,10}$ The start of ER stress is usually a result from affecting ER homeostasis and interfering with proper protein folding, followed by imbalance between protein folding load and capacity, leading to eventual accumulation of unfolded/misfolded proteins in ER lumens that elicit unfolded protein response and ER-associated protein degradation. ${ }^{9,29}$ Several crucial ER stress-related pathways, including the PERK/eIF2 $\alpha /$ ATF4/CHOP, ATF6/ $\mathrm{CHOP}$, and IRE1 $\alpha / \mathrm{CHOP}$, have been revealed to be able to induce apoptosis in cancer cells. ${ }^{9,10,29}$ Our Western blot results showed that treatment with pure HET results in increases in p-PERK, p-eIF2 $\alpha$, ATF4, IRE1 $\alpha$, and CHOP and a decrease in eIF2 $\alpha$, suggesting that HET is capable of eliciting apoptosis via several ER stress-associated pathways in bladder carcinoma cells. HA nanoparticles-aggregated HET at 0.1 and $0.2 \mu \mathrm{g} / \mathrm{mL}$ further enhanced these crucial ER stress apoptotic proteins compared with pure HET, implicating that HA nanoparticle aggregation may strengthen ER stress-related apoptosis induced by pure HET against bladder carcinoma cells. Interestingly, previous works found that biodegraded $\mathrm{HA} / \mathrm{CHI}$ nanoparticle encapsulation enhances apoptosis and/or antitumor effects originally possessed by curcumin and chemotherapeutic similarly via the mitochondrial- or caspase-associated pathways. ${ }^{17,23}$ In the current study, we for the first time revealed that HA nanoparticle-aggregation reinforces the HET-induced apoptosis through the ER stress-associated apoptotic pathways PERK/eIF2 $\alpha /$ ATF4/ CHOP and IRE1 $\alpha /$ CHOP. Treatment with pure HET with increasing concentration caused more obvious changes in caspases than HA nanoparticles-aggregated HET groups, implicating that for pure HET, caspase-dependent pathways should be more essential routes to induce apoptosis in bladder carcinoma cells. HA nanoparticles-aggregated HET, on the other hand, can induce apoptosis via multiple routes, including mitochondrial-related, caspase-dependent and caspase-independent, as well as ER stress-associated pathways, against bladder carcinoma cells. These findings differed from previous results on mitochondrial and caspase-related apoptotic pathways mediated by biodegraded nanoparticlesencapsulated curcumin and chemotherapeutic ${ }^{17,23}$ and further implicated that polymeric nanoparticles may strengthen and diversify apoptotic pathways of compounds. The current results also suggest that HA nanoparticle-aggregation promisingly benefits the anticancer effects of potential and current chemotherapeutics.

Several nonphagocytic intracellular trafficking pathways, including macropinocytosis, clathrin-mediated endocytosis (CME), and caveolae-mediated endocytosis (CvME), have been found to mediate the cellular uptake of nanocarriers. ${ }^{31}$ Although in numerous cell types, CME acts as the chief mechanism of internalization for macromolecules and plasma membrane components, it through specific receptor-ligand interaction plays an even essential role in cellular uptake and intracellular trafficking. However, other mechanisms, such as nonspecific endocytosis via clathrin-coated pits and 
CvME, should not be neglected. Particularly, among the three trafficking mechanisms, CvME enables the process to avoid degradative acidic and enzyme-rich environments like formations of endosome and lysosome. ${ }^{31}$ This may reasonably result in eventual accumulation of nanoparticles in ER and encountering ER processing. We have previously shown that curcumin-loaded HA, CHI, and GEL nanoparticles clearly enhanced the original curcumin-induced apoptosis in NSCLC cell line A549. The mechanisms may be via one or several endocytosis routes, an increase in ROS production, and changes in mitochondrial-related factors like Bcl-2 and BcL-xL. Our previous evidence suggested that the biodegraded polymeric HA, CHI, and GEL nanoparticles may strengthen the induction of apoptosis in NSCLC A549 cells through mitochondrial-associated pathways. ${ }^{17}$ In the current study, we for the first time further revealed that the aggregation of HA nanoparticles is able to reinforce the induction of apoptosis in bladder carcinoma cells via mitochondrialrelated, caspase-dependent, and caspase-independent, as well as ER stress-associated PERK/eIF2 $\alpha /$ ATF4/CHOP and IRE1 $\alpha /$ CHOP pathways. Since several ER stress-associated pathways were included in the apoptosis induced by HA nanoparticles-aggregated HET and ER has been shown as an important destination of CvME, ${ }^{31}$ it is rationally proposed that CvME might be one of cellular uptake and intracellular trafficking routes of HET-loaded HA nanoparticles. Therefore, HET-loaded HA nanoparticles may convey their payloads to ER to cause ER-related cellular responses, including enhancement of ER stress-associated apoptosis; hence, the elevation in ER stress sensors was observed. On the other hand, another promising finding is that polymeric nanoparticles such as poly(butylcyanoacrylate) nanoparticles can enter prostate adenocarcinoma cells via nanoparticle-cell contact-mediated transfer directly to the cytosol. ${ }^{32}$ Whether CvME and the direct transfer exist in the mechanisms of HET-loaded HA nanoparticles requires future work to further ascertain.

Taken together, our study found the cytotoxic, antimigratory, and apoptosis-inducing effects exerted by marine sponge-extracted HET, HA, and CHI nanoparticlesaggregated HET on T24 bladder carcinoma cells. Aggregation of HA nanoparticles significantly ameliorated the originally nonsignificant antitumor activities such as noncytotoxic, nonsignificant apoptosis-inducing and mitochondrial depolarization-causing effects of pure HET at low concentration, indicating that aggregation of HA nanoparticles plays a pivotal role in improving cytotoxic and apoptosisinducing effects of low-concentration HET. Moreover, HA and $\mathrm{CHI}$ nanoparticle aggregations significantly augmented the antimigratory and apoptosis-inducing effects compared with pure HET. Evidence displayed by flow cytometric analysis, JC-1 staining, and Western blot revealed that pure HET and HA nanoparticles-aggregated HET can cause loss of mitochondrial potential and induce subsequent mitochondrial-associated apoptosis in bladder carcinoma cells via caspase-dependent pathways. Data also found that the apoptosis-inducing effects strengthened by HA nanoparticle aggregation were possibly mediated via multiple pathways, including caspase-dependent, caspase-independent, and ER stress-related pathways, which are additional to the existing pure HET-possessed mitochondrial-associated apoptotic pathways. Besides the original caspase-dependent routes of the pure HET, obvious elevation in early/total apoptosis induced by HA nanoparticles-aggregated HET at lower concentrations is highly possible to be mediated via caspaseindependent PARP-1/AIF and ER stress-associated PERK/ eIF2 $\alpha / \mathrm{ATF} 4 / \mathrm{CHOP}$ and IRE1 $\alpha / \mathrm{CHOP}$ pathways. The results uncovered in the present work have paved the way for future application of biodegradable nanoparticles to in vivo antibladder cancer studies using animal models.

\section{Acknowledgment}

This work was funded by a grant (MOST-103-2320-B415-004) from the Ministry of Science and Technology, Taiwan.

\section{Disclosure}

The authors report no conflicts of interest in this work.

\section{References}

1. Pasin E, Josephson DY, Mitra AP, Cote RJ, Stein JP. Superficial bladder cancer: an update on etiology, molecular development, classification, and natural history. Rev Urol. 2008;10(1):31-43.

2. Su CC, Su JH, Lin JJ, et al. An investigation into the cytotoxic effects of 13-acetoxysarcocrassolide from the soft coral Sarcophyton crassocaule on bladder cancer cells. Mar Drugs. 2011;9(12):2622-2642.

3. Burger M, Catto JW, Dalbagni G, et al. Epidemiology and risk factors of urothelial bladder cancer. Eur Urol. 2013;63(2):234-241.

4. Seront E, Machiels JP. Molecular biology and targeted therapies for urothelial carcinoma. Cancer Treat Rev. 2015;41(4):341-353.

5. von der Maase H, Hansen SW, Roberts JT, et al. Gemcitabine and cisplatin versus methotrexate, vinblastine, doxorubicin, and cisplatin in advanced or metastatic bladder cancer: results of a large, randomized, multinational, multicenter, phase III study. J Clin Oncol. 2000;18(17):3068-3077.

6. Roberts JT, von der Maase H, Sengelov L, et al. Long-term survival results of a randomized trial comparing gemcitabine/cisplatin and methotrexate/ vinblastine/doxorubicin/cisplatin in patients with locally advanced and metastatic bladder cancer. Ann Oncol. 2006;17(suppl 5):v118-v122.

7. Loehrer PJ Sr, Einhorn LH, Elson PJ, et al. A randomized comparison of cisplatin alone or in combination with methotrexate, vinblastine, and doxorubicin in patients with metastatic urothelial carcinoma: a cooperative group study. J Clin Oncol. 1992;10(7):1066-1073. 
8. Sternberg CN, Yagoda A, Scher HI, et al. Methotrexate, vinblastine, doxorubicin, and cisplatin for advanced transitional cell carcinoma of the urothelium. Efficacy and patterns of response and relapse. Cancer. 1989; 64(12):2448-2458.

9. Su TR, Lin JJ, Chiu CC, et al. Proteomic investigation of anti-tumor activities exerted by sinularin against A2058 melanoma cells. Electrophoresis. 2012;33(7):1139-1152.

10. Chen YJ, Su JH, Tsao CY, et al. Sinulariolide induced hepatocellular carcinoma apoptosis through activation of mitochondrial-related apoptotic and PERK/eIF2alpha/ATF4/CHOP pathway. Molecules. 2013;18(9):10146-10161.

11. Ledroit V, Debitus C, Ausseil F, Raux R, Menou J-L, Hill B. Heteronemin as a protein farnesyl transferase inhibitor. Pharm Biol. 2004;42(6): 454-456.

12. Chang YC, Tseng SW, Liu LL, et al. Cytotoxic sesterterpenoids from a sponge Hippospongia sp. Mar Drugs. 2012;10(5):987-997.

13. Schumacher M, Cerella C, Eifes S, et al. Heteronemin, a spongean sesterterpene, inhibits TNF alpha-induced NF-kappa B activation through proteasome inhibition and induces apoptotic cell death. Biochem Pharmacol. 2010;79(4):610-622.

14. Mahapatro A, Singh DK. Biodegradable nanoparticles are excellent vehicle for site directed in-vivo delivery of drugs and vaccines. J Nanobiotechnology. 2011;9:55.

15. Egusquiaguirre SP, Igartua M, Hernandez RM, Pedraz JL. Nanoparticle delivery systems for cancer therapy: advances in clinical and preclinical research. Clin Transl Oncol. 2012;14(2):83-93.

16. Sun Q, Teong B, Chen IF, Chang SJ, Gao J, Kuo SM. Enhanced apoptotic effects of dihydroartemisinin-aggregated gelatin and hyaluronan nanoparticles on human lung cancer cells. J Biomed Mater Res B Appl Biomater. 2014;102(3):455-462.

17. Teong B, Lin CY, Chang SJ, et al. Enhanced anti-cancer activity by curcumin-loaded hydrogel nanoparticle derived aggregates on A549 lung adenocarcinoma cells. J Mater Sci Mater Med. 2015;26(1):5357.

18. Siddiqui MA, Alhadlaq HA, Ahmad J, Al-Khedhairy AA, Musarrat J, Ahamed M. Copper oxide nanoparticles induced mitochondria mediated apoptosis in human hepatocarcinoma cells. PLoS One. 2013;8(8): e69534.

19. Lan MY, Hsu YB, Hsu CH, Ho CY, Lin JC, Lee SW. Induction of apoptosis by high-dose gold nanoparticles in nasopharyngeal carcinoma cells. Auris Nasus Larynx. 2013;40(6):563-568.

20. Choi KY, Saravanakumar G, Park JH, Park K. Hyaluronic acid-based nanocarriers for intracellular targeting: interfacial interactions with proteins in cancer. Colloids Surf B Biointerfaces. 2012;99:82-94.
21. Bilensoy E. Cationic nanoparticles for cancer therapy. Expert Opin Drug Deliv. 2010;7(7):795-809.

22. Prestwich GD, Marecak DM, Marecek JF, Vercruysse KP, Ziebell MR Controlled chemical modification of hyaluronic acid: synthesis, applications, and biodegradation of hydrazide derivatives. J Control Release. 1998;53(1-3):93-103.

23. Vivek R, Thangam R, Nipunbabu V, Ponraj T, Kannan S. Oxaliplatinchitosan nanoparticles induced intrinsic apoptotic signaling pathway: a "smart" drug delivery system to breast cancer cell therapy. Int J Biol Macromol. 2014;65:289-297.

24. Liao MH, Liu SS, Peng IC, Tsai FJ, Huang HH. The stimulatory effects of alpha1-adrenergic receptors on TGF-beta1, IGF-1 and hyaluronan production in human skin fibroblasts. Cell Tissue Res. 2014; 357(3):681-693.

25. Salido M, Gonzalez JL, Vilches J. Loss of mitochondrial membrane potential is inhibited by bombesin in etoposide-induced apoptosis in PC-3 prostate carcinoma cells. Molecular Cancer Therapeutics. 2007;6(4): 1292-1299.

26. Bhattacharya S, Ahir M, Patra P, et al. PEGylated-thymoquinonenanoparticle mediated retardation of breast cancer cell migration by deregulation of cytoskeletal actin polymerization through miR-34a. Biomaterials. 2015;51:91-107.

27. Yang JA, Phan HT, Vaidya S, Murphy CJ. Nanovacuums: nanoparticle uptake and differential cellular migration on a carpet of nanoparticles. Nano Lett. 2013;13(5):2295-2302.

28. Moenner M, Pluquet O, Bouchecareilh M, Chevet E. Integrated endoplasmic reticulum stress responses in cancer. Cancer Res. 2007; 67(22):10631-10634.

29. Verfaillie T, Garg AD, Agostinis P. Targeting ER stress induced apoptosis and inflammation in cancer. Cancer Lett. 2013;332(2):249-264.

30. Yang J, Wei J, Wu Y, et al. Metformin induces ER stress-dependent apoptosis through miR-708-5p/NNAT pathway in prostate cancer. Oncogenesis. 2015;4:e158.

31. Hillaireau H, Couvreur P. Nanocarriers' entry into the cell: relevance to drug delivery. Cell Mol Life Sci. 2009;66(17):2873-2896.

32. Snipstad S, Westrom S, Morch Y, Afadzi M, Aslund AK, de Lange Davies C. Contact-mediated intracellular delivery of hydrophobic drugs from polymeric nanoparticles. Cancer Nanotechnol. 2014;5(1):8.

33. Huang HH, Brennan TC, Muir MM, Mason RS. Functional alpha1- and beta2-adrenergic receptors in human osteoblasts. J Cell Physiol. 2009; 220(1):267-275.
International Journal of Nanomedicine

\section{Publish your work in this journal}

The International Journal of Nanomedicine is an international, peerreviewed journal focusing on the application of nanotechnology in diagnostics, therapeutics, and drug delivery systems throughout the biomedical field. This journal is indexed on PubMed Central, MedLine, CAS, SciSearch $®$, Current Contents $\AA /$ Clinical Medicine,

\section{Dovepress}

Journal Citation Reports/Science Edition, EMBase, Scopus and the Elsevier Bibliographic databases. The manuscript management system is completely online and includes a very quick and fair peer-review system, which is all easy to use. Visit http://www.dovepress.com/ testimonials.php to read real quotes from published authors. 